\title{
PERFIL DE COMERCIALIZAÇÃO DAS ANONÁCEAS NAS CEASAS BRASILEIRAS ${ }^{1}$
}

\author{
HÉLIO SATOSHI WATANABE ${ }^{2}$, SABRINA LEITE DE OLIVEIRA ${ }^{3}$, FABIANE MENDES DA CAMARA ${ }^{4}$, \\ GABRIEL VICENTE BITENCOURT DE ALMEIDA ${ }^{5}$, ANDRÉ AFONSO ALVES ${ }^{6}$
}

RESUMO -A quantidade de anonáceas comercializadas nas principais centrais de abastecimento está crescendo e concentrada na CEAGESP - 61\%. As informações coletadas pelo SIEM da CEAGESP mostram, entre 2011 e 2012, o grande crescimento da oferta de atemoia e de graviola, respectivamente, $35 \%$ e $32 \%$, entre 2011 e 2012, e a queda do volume de pinha - 20\%, entre 2011 e 2012. A atemoia (54\%), a pinha (41\%) e a graviola (5\%) são as anonáceas mais importantes comercializadas na CEAGESP. A origem é concentrada nos Estados da Bahia - pinha e graviola, e em Minas Gerais e São Paulo - atemoia. O estudo das causas da diferenciação de valor, entre lotes de atemoia de valores máximo e mínimo, de mesma classificação de tamanho, no mesmo dia, mostrou que a homogeneidade visual de tamanho é a maior responsável pela diferenciação de valor. A melhoria da seleção por tamanho é a melhor estratégia de diferenciação de valor a ser adotada pelo produtor.

Termos para indexação: valor, CEAGESP, graviola, pinha, atemoia.

\section{ANNONA'S MARKETING PROFILE AT BRAZILIAN TERMINAL MARKETS}

ABSTRACT - The anonas' quantity at Brazilian main terminal markets is growing and is concentrated at CEAGESP - 61\%. SIEM's data has shown a large supply growth of atemoya and soursop, $35 \%$ and $32 \%$ respectively, and a sweetsop's decrease - 20\%, from 2011 to 2012 at CEAGESP. Atemoya (54\%), soursop $(41 \%)$ and sweetsop (5\%) are the most important anonnas at CEAGESP terminal market. The origin is concentrated in the state of Bahia - soursop and sweetsop and atemoya from Minas Gerais and São Paulo. The study of the value differentiation causes, comparing atemoya batches of the same grade size, of maximum and minimum value, at the same day, has shown the size homogeneity as the most important characteristic for value differentiation. The best strategy to promote the value differentiation for the grower is to improve size selection - its visual homogeneity.

Index terms: CEAGESP, soursop, sugar apple or sweetsop, atemoya, quality.

\footnotetext{
${ }^{1}$ Palestra Anonáceas - V Congresso Internacional \& Encontro Brasileiro sobre Annonaceae: do gene à exportação (19 a 23 de Agosto de 2013). Botucatu-SP.

${ }^{2}$ Engenheiro. Agrônomo, CEAGESP. E-mail: hwatanabe@ceagesp.gov.br

${ }^{3}$ Engenheira Agrônoma, Mestre em Tecnologia Pós-Colheita, CEAGESP. E-mail: sloliveira@ceagesp.gov.br

${ }^{4}$ Engenheira de Alimentos, Mestre em Ciência e Tecnologia de Alimentos, CEAGESP. E-mail: fcamara@sp.gov.br

${ }^{5}$ Engenheiro Agrônomo, Doutorando Faculdade de Ciências Agronômicas (FCA) da Universidade Estadual Paulista "Júlio de Mesquita Filho" (UNESP) de Botucatu-SP, CEAGESP. E-mail: gabriel.bitencourt@gmail.com

${ }^{6}$ Engenheiro Agrônomo. E-mail: andre@viapomme.com.br
} 


\section{INTRODUÇÃO}

Anonácea é o nome genérico que designa as plantas da família botânica Annonaceae, e de 100 espécies, sendo apenas cinco com importância comercial: a graviola (A. muricata L.), a pinha, ata ou fruta-do-conde (A. squamosa L.), a cherimólia (A. cherimola Mill.), a condessa (A. reticulata L.) e a atemoia (híbrido de $A$. cherimolia x A. squamosa) (PAREEK et al., 2011).

Sua comercialização nas centrais de abastecimento está concentrada na Companhia de Entrepostos e Armazéns Gerais de São Paulo CEAGESP, com $61 \%$ do volume comercializado nas 15 maiores Centrais Atacadistas - Ceasas, em 2012, seguida pela CEASA do Rio de Janeiro com 29\% (CONAB, 2013).

O volume de anonáceas comercializado na CEAGESP está crescendo a cada ano, como mostra a Figura 1. O volume de 6.420 toneladas de anonáceas comercializado foi $11 \%$ superior ao de 2011 (SIEM, 2013).

A principal espécie comercializada é a atemoia, seguida pela pinha e pela graviola, e apesar de algumas outras espécies de anonáceas serem encontradas na CEAGESP, o volume ainda é pequeno e, por esse motivo, não há registros (Figura 2) (SIEM, 2013).

A origem predominante das anonáceas comercializadas na CEAGESP, em 2012, por 99 atacadistas, está concentrada em três Estados: Bahia (39\%), seguida de São Paulo (30\%) e Minas Gerais (29\%), e sua oferta nos meses de junho a agosto (SIEM, 2013).

A análise do comportamento no mercado das três principais anonáceas (graviola (A. muricata L.); pinha, ata ou fruta-do-conde (A. squamosa L.) e atemoia (híbrido de $A$. cherimolia $\mathrm{x}$ A. squamosa)) é relevante na tomada de decisão de produtores e comerciantes.

\section{Tópicos do tema abordado Graviola}

A graviola é utilizada para obtenção de polpa, suco, néctar, entre outros. Embora a importância comercial no Brasil seja considerada de baixa expressão em relação a outras frutas, o crescente interesse por parte da indústria de suco faz com que a graviola se torne promissora para exportação (SAMARAO et al., 2011). Sua oferta no mercado de fruta fresca está crescendo, como mostram os dados da CEAGESP de crescimento da oferta entre 2011 e 2012, de 32\%, chegando a 379 toneladas em 2012, sendo os meses de maiores ofertas janeiro, agosto e dezembro. A comercialização é concentrada em $9(90 \%)$ dos 29 atacadistas, e a origem nos Estados da Bahia e São Paulo - 90\% e 7\%, respectivamente (SIEM, 2013).

\section{Pinha}

A pinha, também conhecida como ata ou fruta-do-conde, é muito apreciada pelos nordestinos e pelos paulistanos e está presente nas centrais de abastecimento de todo o Brasil (DIAS et al., 2004).

O volume de pinha registrado em 2012, de 2.223 toneladas na CEAGESP, é $20 \%$ inferior ao de 2011 (Figura 1). Ela é comercializada por 54 atacadistas, que a recebem dos Estados da Bahia $76 \%$ e de São Paulo - 11\%.

Fevereiro foi o mês de maior entrada de pinha na CEAGESP - 371 toneladas, e o de novembro, com 63 toneladas, o de menor entrada (SIEM, 2013).

\section{Atemoia}

O consumo de atemoia está em franco crescimento (FIRMINO, 2012). O volume comercializado entre 2007 e 2012 mais que dobrou, e seu preço médio apresentou pequena queda entre 2011 e 2012 (Figura 4) (SIEM, 2013).

Os Estados de Minas Gerais e São Paulo dominaram, em 2012, o fornecimento da atemoia comercializada na CEAGESP, com 95\% do volume, seguidos pela Bahia, Paraná, e Pernambuco (Figura 5) (SIEM, 2013).

A amplitude de mercados no cenário vigente estimula a competitividade e a busca de eficiência e eficácia para garantir rentabilidade continuada (ROMBALDI et al., 2007). Existe grande diferenciação de valor, por qualidade e tamanho, na venda do atacado para o varejo, no mercado da CEAGESP (OLIVEIRA et al., 2012). É preciso compreender quais atributos de qualidade são mais valorizados, para definir estratégias para o aumento do consumo e da receita do produtor.

O Centro de Qualidade em Horticultura da CEAGESP desenvolveu uma metodologia de determinação de que atributos são responsáveis pela valoração do produto e da importância de cada um deles na diferenciação de valor, que obedece às seguintes etapas:

A $1^{a}$ Etapa trata da definição dos principais atributos de qualidade da atemoia, baseada na experiência dos atacadistas e varejistas que comercializam na CEAGESP.

A $2^{\text {a }}$ Etapa trata do desenvolvimento de um gabarito de avaliação visual de qualidade, com fotos, com aferição de nota de 1 a 10, sendo a nota 1 para a pior qualidade e a nota 10 para a melhor qualidade 
de cada atributo.

A $3^{\text {a }}$ Etapa trata da coleta, no mesmo dia, de lotes de mesma classificação de tamanho, de maior e menor preço e da avaliação de seus atributos de qualidade, com o gabarito desenvolvido na $2^{\mathrm{a}}$ etapa.

A $4^{a}$ Etapa trata da análise das informações levantadas, através da comparação entre as avaliações de qualidade por atributo dos lotes de maior e menor preços, do cálculo da razão entre as notas de cada atributo e entre os preços praticados em cada dia de avaliação.

A avaliação da qualidade da atemoia foi realizada, a cada semana, entre 09 de julho de 2012 e 18 de janeiro de 2013 , durante 25 semanas, num total de 50 lotes. A homogeneidade de tamanho dos frutos na caixa, a maturação, a ocorrência e a gravidade de dano mecânico, de defeito de casca e de defeito de formação, a sanidade e a ocorrência de defeito de polpa foram os atributos avaliados.

A diferença \% média de valor, entre os lotes de maior e menor preço, no mesmo dia, foi de $50 \%$, chegando a mais de $100 \%$ em algumas semanas.

$\mathrm{O}$ atributo mais importante na diferenciação de valor é a homogeneidade de tamanho, que apresenta a maior razão média entre as notas dos lotes de maior e menor preço no mesmo dia, o que torna a melhoria da classificação a principal estratégia de diferenciação de valor (Figura 6).

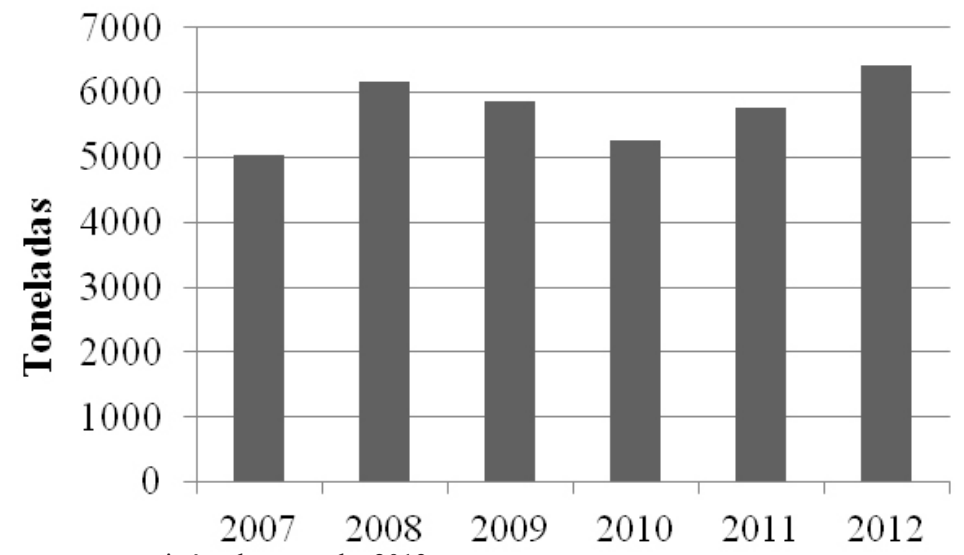

Fonte: Sistema de informação e estatistíca de mercado, 2013.

FIGURA 1 - Evolução do volume de anonáceas, em toneladas, comercializadas na CEAGESP entre 2007 e 2011.

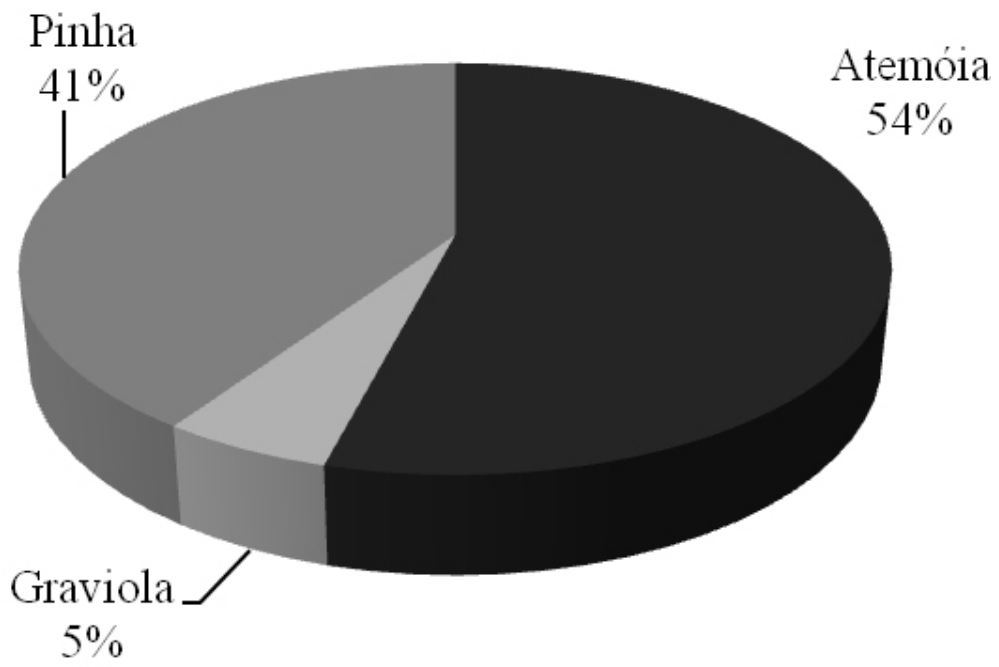

Fonte: Sistema de informação e estatistíca de mercado, 2013.

FIGURA 2 - Participação em \% das anonáceas comercializadas na CEAGESP em 2012. 


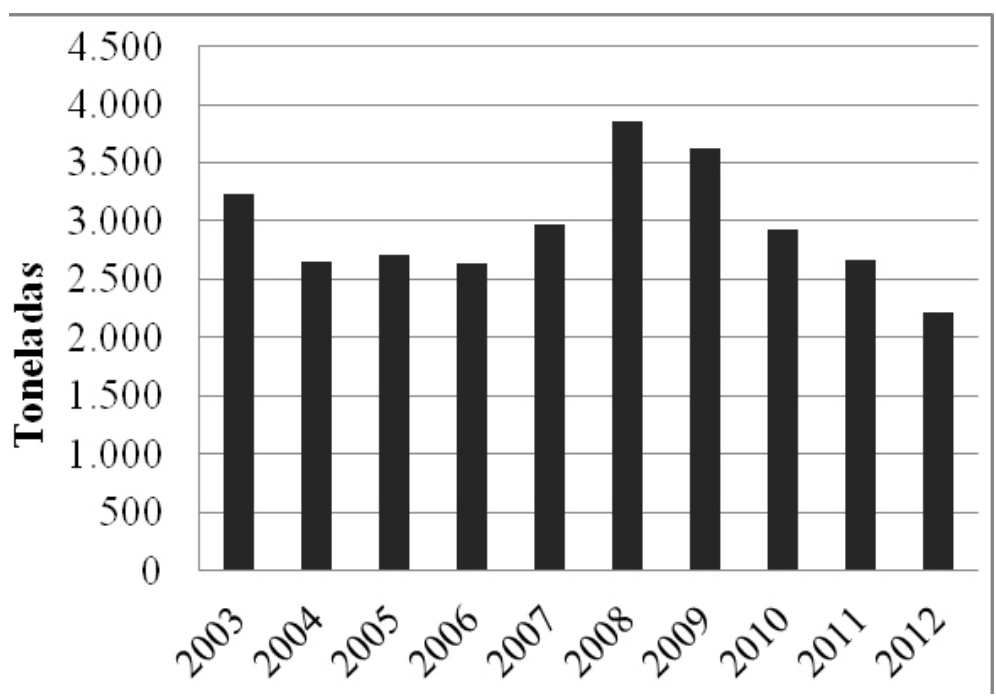

Fonte: Sistema de informação e estatistíca de mercado, 2013.

FIGURA 3 - Evolução do volume, em toneladas, da pinha comercializada na CEAGESP,entre 2003 e 2012.

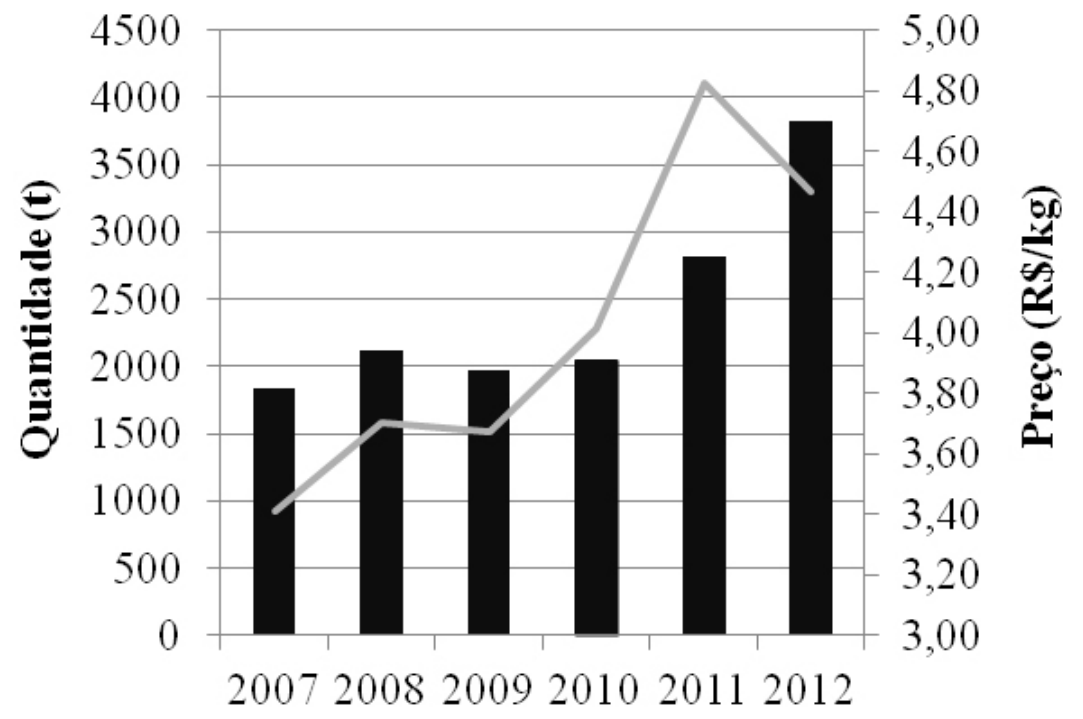

Quantidade Preço médio

Fonte: Sistema de informação e estatistíca de mercado, 2013.

FIGURA 4 - Evolução do volume e do preço médio da atemoia comercializada na CEAGESP, entre 2007 e 2012. 


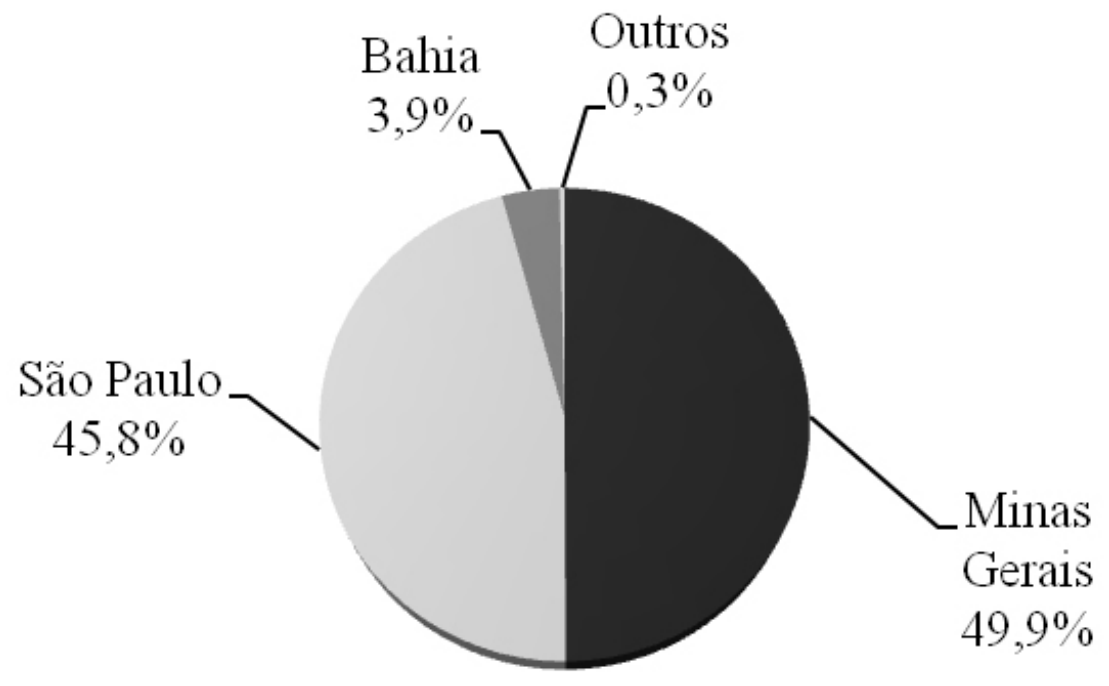

Fonte: Sistema de informação e estatistíca de mercado, 2013.

FIGURA 5 - Participação em \% dos principais estados de origem de atemoia, na CEAGESP em 2012.

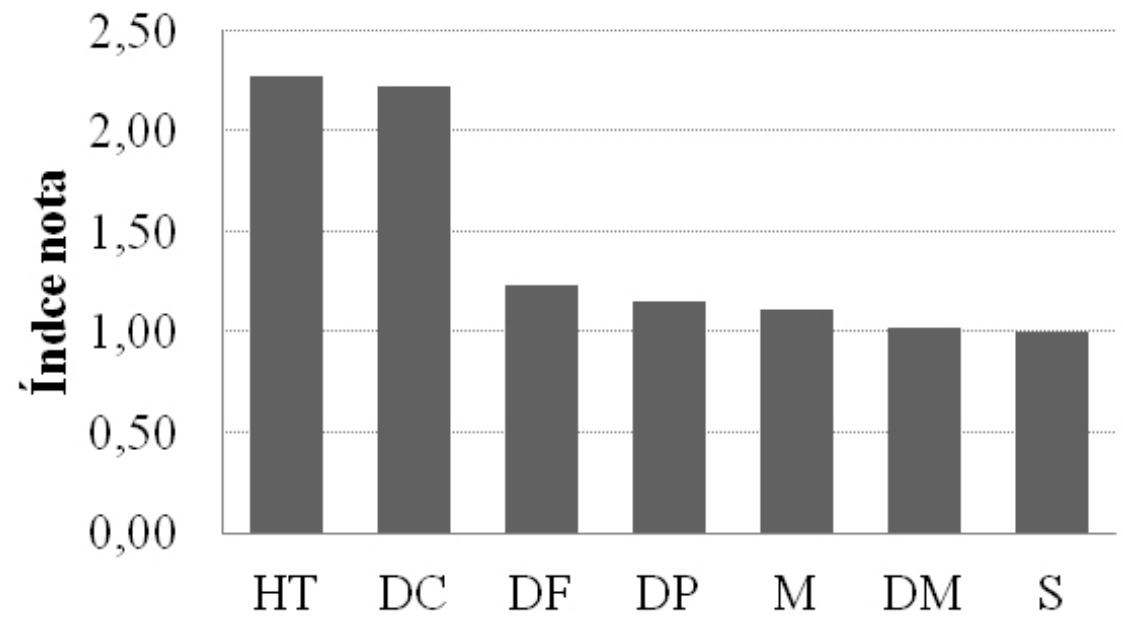

Atributos de qualidade da atemóia

FIGURA 6 - Razão média entre as notas dos lotes de atemoia, de maior e menor preço, por atributo de qualidade. Atributos de qualidade da atemoia: $\mathrm{HT}=$ Homogeneidade do tamanho do fruto na caixa; DC = Defeito de casca; $\mathrm{DF}=$ Defeito deformação; $\mathrm{DP}=$ Defeito de polpa; $\mathrm{M}=$ Maturação; DM = Dano mecânico, e S = Sanidade. 


\section{CONCLUSÃO}

1-A oferta total de anonáceas no mercado da CEAGESP está crescendo, pelo grande crescimento da oferta de atemoia e de graviola, respectivamente, $35 \%$ e $32 \%$, entre 2011 e 2012 . O volume de pinha está caindo, $20 \%$ entre 2011 e 2012 . A atemoia (54\%), a pinha $(41 \%)$ e a graviola (5\%) são as anonáceas mais importantes.

2-O Estado da Bahia foi o maior fornecedor de pinha e graviola, e Minas Gerais de atemoia em 2012, na CEAGESP.

3-Os atributos de qualidade mais importantes na diferenciação de valor da atemoia são a homogeneidade visual de tamanho e a ocorrência de defeito de casca.

4-A compreensão da importância de cada atributo de qualidade na valoração do produto permite a definição de uma estratégia de diferenciação de valor pelo produtor e de negociação entre o produtor e seu comprador.

\section{REFERÊNCIAS}

CONAB - Companhia Nacional de Abastecimento. Programa brasileiro de modernização do mercado hortigranjeiro-PROHORT. Disponível em: <http://dw.prohort.conab.gov.br/pentaho/ Prohort>. Acesso em: 20 jan. 2013.

DIAS, N.O.; SOUZA, I.V.B.; SILVA, J.C.G.; SILVA, K.S.; BOMFIM, M.P.; ALVES, J.F.T.; REBOUÇAS. T.N.H.; VIANA, A.E.S.; SÃO JOSÉ, A.R. Desempenho vegetativo e reprodutivo da pinheira em função de diferentes comprimentos de ramos. Revista Brasileira de Fruticultura, Jaboticabal, v. 26, n. 3, p. 389-391, 2004.

FIRMINO, A.C.et al. Ceratocystis fimbriata causando murcha em atemóia na região de BotucatuSP. Summa Phytopathologica, Botucatu, v. 38, n. 2, p 171-171, 2012.

ROMBALDI, C.V; TIBOLA, C.S.; FACHINELLO, J.C.; SILVA, J.A. Percepção de consumidores do Rio Grande do Sul em relação a quesitos de qualidade de frutas. Revista Brasileira de Fruticultura, Jaboticabal, v.29, n.3, p.681-684, 2007.
SIEM - Sistema de Informação e Estatística de Mercado da Companhia de Entrepostos e Armazéns Gerais de São Paulo. São Paulo: CEAGESP, 2013. Não publicado.

PAREEK, S.; YAHIA, E.M.; PAREEK, O.P.; KAUSHIK, R.A. Postharvest physiology and technology of Annona fruits. Food Research International, Barking, v. 44, p. 1741-1751, 2011.

SAMARAO, S.S.; RODRIGUES, L.A.; MARTINS, M.A.; MANHÃES, T.N.; ALVIM, L.A.M. Desempenho de mudas de gravioleira inoculadas com fungos micorrízicos arbusculares em solo nãoesterilizado, com diferentes doses de fósforo. Acta Scientiarum Agronomy, Maringá, v. 33, n. 1, p. 81-88, 2011.

OLIVEIRA, S.L. et al. Valoração dos atributos de Qualidade fazer tomate de mesa: um estudo com atacadistas da CEAGESP. Horticultura Brasileira, Brasília, v. 30, n. 2, p. 214-219, 2012. 